\title{
Sexo, gênero. Sintoma e sinthoma
}

\section{Sheila Abramovitch}

O tema do transexualismo encontra-se em destaque em nossa sociedade, e na clínica psicanalítica começam a chegar sujeitos que também nos endereçam essa questão. Como a psicanálise pode contribuir para o estudo do transexualismo? Sexo e gênero, sintoma e sinthoma serão cotejados no percurso deste texto. Apresento dois exemplos, nos quais sujeitos, em cuja certidão de nascimento estava escrito "sexo feminino", diziam sentir-se do sexo masculino - João Nery e Julia.

Transexualismo é um termo criado pelo endocrinologista alemão-americano Harry Benjamim, que em 1953, sob o olhar da clínica médica, estabelece limites e marcadores verificáveis e diferenciados entre travestis, trans e homossexuais. Propõe o alívio do sofrimento moral por meio de tratamentos com hormônios e uma experiência no socius com o sexo proposto. Caso o desejo persista, a cirurgia para redesignação de sexo é indicada (BENJAMIM, 1953).

Para Lacan, entretanto,"o transexualismo consiste, precisamente, num desejo muito enérgico de passar, seja por que meio for, para o sexo oposto, nem que seja submetendo-se a uma operação, quando se está do lado masculino" (LACAN, 1971a/2009, p. 30). Refere, também, à paixão do transexual de "querer forçar pela cirurgia o discurso sexual, que, na medida em que é impossível, é a passagem do real” (LACAN, 1971b/2012, p.17). Chamamos a atenção, nessas passagens, para o fato de a medicina nomear de "transexuais masculinos" os sujeitos que autodesignam de "transmulheres"; vê-se então que, no discurso médico, o nome se refere ao sexo anterior à operação de transição, enquanto que no discurso dos próprios sujeitos, o significante indica o assim chamado "sexo psíquico", alma ou gênero, conforme o laço social em que esteja implicado.

$\mathrm{Na}$ atualidade, a mudança de sexo é amparada pelo discurso da ciência. Como nos diz Catherine Millot, "não há transexual sem cirurgião e nem sem endocrinologista" (MILLOT, 1992, p. 17). Como o sexo biológico nem sempre coincide com o sexo psíquico de um sujeito, já que a natureza não é tão caprichosa assim, gens nunca determinaram e nem foram limite para o gozo sexual. Mas se a medicina pode mudar o corpo biológico do ser falante, ela não pode ignorar a problemática em torno da identidade sexual; deveria levar em conta a distinção entre a escolha de gozo de um sujeito, que o leva a dizer-se "homem" ou "mulher", e sua escolha de objeto/parceiro sexual, que será dita hetero ou homo. Nos seres falantes, as escolhas sexuais não são da ordem das identidades, mas das identificações, ou seja, são condicionadas pelos ditos do Outro simbólico, levando, por vezes, a mudanças no corpo próprio e à busca por reconhecimento social. 
Para pensarmos a demanda de uma menina querer tornar-se menino, recorro a Freud em A dissolução do complexo de Édipo, em que recupera o dito de Napoleão Bonaparte "a geografia é o destino", criando a polêmica frase "a anatomia é o destino" (FREUD, 1924/1996, p. 197). Entendemos destino, com Lacan (1973/1998), como o Outro da linguagem, portador de significantes e engendrando a escolha forçada do sujeito. Freud aponta no texto acima para o limite do corpo real e propõe saídas para o complexo edipiano na menina, determinadas pela inveja do pênis.

Para Freud (1924/1996) todos os seres humanos, independentemente do sexo a que pertençam, desenvolvem complexo de Édipo, supereu e latência. Ele se pergunta, contudo, sobre as particularidades da fase fálica e do complexo de castração nas meninas, pois elas se sentem injustiçadas, quando comparam seu órgão genital com o de um menino, advindo-lhes o "fundamento para inferioridade" (Ibid., pp. 197-198).

Em A diferença anatômica entre os sexos, Freud retoma o termo "complexo de masculinidade", de Van Ophuijsen, para sinalizar que a menina pode ter dificuldades no caminho em direção à feminilidade, inclusive a ilusão, aos moldes de uma fantasia inconsciente, de que algum dia ainda obterá um pênis: "Ela o viu, sabe que não o tem e quer tê-lo" (1925/1996, p. 281). Por isso, poderá assemelhar-se a um homem na vida adulta, o que será "motivo para ações estranhas e doutra maneira inexplicáveis" (Ibid., p. 281).

A menina pode, ainda, "recusar o fato de ser castrada, enrijecer-se na convicção de que realmente possui um pênis e subsequentemente ser compelida a comportar-se como se fosse um homem" (FREUD, 1925/1996, p. 282). Freud acrescenta que o mecanismo de Verleugnung, desmentido da castração, comum nas crianças, é possível de ser encontrado nas mulheres maduras. Contudo, neste caso, pode significar o começo de uma psicose.

À guisa de ilustração, trazemos João Nery, autonomeado o primeiro transexual do Brasil, que, com uma laçada, reinventa um lugar para si no mundo ao construir um sinthoma, pois, para ele, ser um transhomem faz nó. Ele dedica sua autobiografia Viagem Solitária - Memórias de um transexual 30 anos depois (NERY,2011) a todos aqueles que se reinventam. Narra sua infância triste e confusa, por nascer menino num corpo de menina. Desde muito cedo, esse drama se apresenta como uma vivência de discordância do sujeito com sua própria imagem corporal diante do espelho.

Todos o viam como menina, mas, segundo ele, isso era um engano. Adorava as brincadeiras dos garotos, sonhava ser um super-herói, se casar com uma princesa e ser pai. Chamado de Maria-homem, em determinado Natal pedira uma roupa de cowboy, cheia de franjas e duas pistolas. E, ao apagar as velas de oito anos, fez um pedido: "quero ser um menino como os outros" (NERY, 2011, p. 35).

Para fugir desse mal-estar refugia-se na fantasia. Assim, seria reconhecido e sobreviveria. Nery diz que: 
[...] devido a esta absurda defasagem entre minha autoimagem e a que faziam de mim, descobri, quase que instintivamente, que na fantasia estaria a gratificação de ser reconhecido. Considero essa solução a balsa salva-vidas com a qual consegui sobreviver a tantos desencontros... moldei-a de uma forma que podia adaptá-la àrealidade (Ibid., pp. 35-36).

Quando chamado de "ela", o pensamento transformava imediatamente em “ele". Criou os personagens Zé, Zeca e Zico para poder brincar com a irmã e com a prima, podendo, dessa forma, ser tratado no masculino. Esses personagens eram três viúvos, que não tinham esposas, mas possuíam muitas bonecas-filhos. Trabalhavam como empregados domésticos e agradavam aos patrões. Assim sentia-se útil, já que em sua casa as crianças eram pouco ouvidas.

Namorou algumas moças, mas ao olhar-se no espelho horrorizava-se ao pensar que tudo estava fora do lugar, "o que sobrava em cima, faltava embaixo". Achava-se um aleijão e puxava o clitóris com força para ver se aumentava de tamanho. De sua história sabemos que é o único filho homem entre quatro irmãs. "O pai aviador, brincalhão; e a mãe, professora, seca, econômica e coerente na educação” (Ibid., p. 29).

A adolescência "transtornada", iniciada com a "monstruação" (Ibid., p. 14) e o crescimento dos seios, fez com que João ousasse fazer mastectomia radical. Começa, assim, a história de um homem trans operado no Brasil. João afirmava que nascera mulher, mas sentia-se aprisionado num corpo estranho, desde sempre.

Abriu mão da profissão de psicólogo e professor, perdendo emprego e status, além de ir de encontro à sua família. Ele diz que ocorreu um erro na sua pessoa (NERY, 1984), não era Joana, mas João. Uma vida repleta de dramas, incompreensões e de muitas lutas enfrentadas. Durante a ditadura militar, submeteu-se à primeira cirurgia. Naquela época, as clínicas e os hospitais não estavam habilitados a realizá-la, e os médicos que a faziam eram considerados mutiladores e cassados. A busca incessante por documentos e por uma identidade social masculina acompanhou sua luta, e não o abandonou jamais (NERY, 2011).

Segundo a teoria lacaniana, são os desencontros com o real que causam as marcas do sexual. Nenhum sentido ou objeto pode satisfazer a pulsão, pois o sexual é o ponto cego do simbólico. Apesar de a pulsão dispor de maneiras variadas de situar mulheres e homens, nenhum objeto será capaz de satisfazê-la (LACAN, 1962-63/2005).

Passemos agora para o exemplo clínico. Julia, adolescente de doze anos, comparece ao consultório após tentativa de suicídio. Tomara medicamentos encontrados no armário de sua mãe. Segundo relato dos pais, encontrava-se deprimida, em tratamento psiquiátrico, e haviam notado, também, que se cortava nos braços e nas pernas.

Julia é filha caçula e tem um irmão dez anos mais velho. Moça tímida, contou-me, sussurrando, logo na primeira entrevista, que "não se sentia menina e desejava se tornar um menino". Estava apressada para voltar para casa e concluir um trabalho 
escolar sobre o livro Werther, de Goethe. Indagada sobre o desfecho do livro - suicídio do protagonista por um amor não correspondido -, limitou-se a responder que gostara muito da leitura, não associando nada à sua própria história.

Mas o que antecedeu à tentativa de suicídio e levou Julia a esse extremo? A jovem, já em análise, revela não ter suportado representar, na escola, o papel da Julieta, de Shakespeare: “Isso foi demais, era muita feminilidade!”. Na tentativa de encontrar um significante que a represente, entre séries de TV, livros e músicas, toma emprestado a figura da Julieta - tentativa de identificação com um objeto amável pelo Outro materno, a de ser menina e feminina. Mas não suportou estar nesse lugar, o que a levou ao ponto de ruptura.

Fã da série Game of Thrones e da banda de rock AC/DC, tem discussões com sua mãe, por esta considerar suas escolhas mórbidas e incomuns. Julia alega que, apesar de serem imersas em obscurantismo, são poéticas, e não entende o porquê de tantas brigas. Em seu status do whatsApp se apresenta assim: "Aqui mora um vampiro", e acrescenta uma figurinha de uma seringa pingando gotas de sangue.

Julia fala da mãe com raiva, pelo fato de ela a impedir de andar sozinha ou de se encontrar com amigos, mas ela é a quem recorre quando tem enxaqueca, TPM e até desmaios. Relata, em uma determinada sessão, ter sonhado com um arco-íris: "Meu corpo não me pertence", diz. "Como eu achei que isso era real? Agora não quero mais! Estou cheia de fazer o que os outros querem de mim!”. Começou, então, a usar roupas masculinas e a retirar as insígnias femininas de seu corpo, como brincos e colares. Foi então que surgiu umdesejo irresistível de cortar o cabelo bem curtinho: “O cabelo comprido me incomoda, não gosto dessa coisa na nuca, dá muito calor!”.

Para amenizar o clima de tensão, gerado pela insistência em usar seu cabelo à la garçon, sugere aos pais uma viagem diferente. Uma viagem do tipo easy rider, sem roteiro, decidindo-se a cada momento o próximo destino. "Pura armação!", diz. Descobre, durante o caminho, que já estava tudo previamente determinado, as rotas, as cidades, os hotéis e restaurantes, e conclui que sempre a fizeram de boba. Desiste, então, de escolher por seu próprio desejo e volta a se deprimir.

A posição de boba aparece na transferência ao não querer saber o quanto me paga, no trocar os dias das sessões e, às vezes, pedir para eu repetir o que falo. Em seguida à viagem, sua mãe me pede uma sessão conjunta. Preocupada com a tristeza da filha, pede o meu testemunho para aceitar a escolha de Julia cortar o cabelo, pois esta dependeria também da sua aprovação. Julia olha para a mãe e lhe diz: "Precisei aumentar o volume ao máximo para você poder me ouvir?" A mãe concorda e impõe-lhe uma condição: que Julia conte ao pai sua ideia de mudar sua aparência. "Ele não é um idiota! Não pode ficar de fora!"

Julia fala nas sessões seguintes do quanto não quer decepcionar seu pai, e lembra de brigas que ouvia entre ele e seu irmão, por causa de dinheiro. Julia não quer perder o lugar privilegiado no desejo paterno - sua xodó -, por isso, diz que "não briga, não discute... não fala”. 
A partir do corte de cabelo, iniciam-se as transformações de Julia: o cabelo longo e bonito dá vez ao "taradinho", as roupas largas e disformes substituem as coladinhas, e o seu semblante se torna o de um menininho. Decidiu não fazer mais o que os outros queriam dela. Chega! Muda seu status no WhatsApp para be what you are (seja o que você é) e faz uma atuação. Deixa a análise, dizendo que não a ouço e me troca por um homem: "analista homem é melhor que mulher", disse-me.

Vemos aí uma reivindicação fálica por parte de Julia; demanda à mãe algo que ela não pode lhe dar, assim como a analista, suposto saber furado e que também é castrada. A analista não pode sustentar o lugar idealizado pela paciente, de que homem é melhor do que mulher. Ao perceber que a analista tampouco poderia responder à sua reivindicação fálica, faz um acting out interrompendo a análise.

Lacan vem ao nosso encontro ao dizer que o sujeito, em suas constantes tentativas de se adaptar ao real, faz amarrações e desamarraçōes, enlaces e desenlaces (LACAN, 1974-75/2007). A diferença sexual, contudo, é um dado da estrutura do ser falante, uma vez que o discurso, com os seus significantes, determina o sexo do sujeito. Desde o nascimento, ser menino ou menina, já está escrito no corpo, por meio dos efeitos da linguagem sobre as identificações e escolhas objetais do sujeito, o que não permite que essas escolhas sejam livres, pois a criança já é falada, muito antes de ela nascer, já é "um polo de atributos, eis o que é o sujeito antes de seu nascimento" (LACAN, 1960/1998, p. 659).

Ao aforismo freudiano "a anatomia é o destino", podemos acrescentar os desenvolvimentos do Seminário 23 de Lacan, acerca do movimento da pulsão que, ao tentar contornar o objeto $a$, vai transformando o mal-estar do sintoma em um sinthoma particular, sua singularidade-sintoma (LACAN, 1974-75/2007). A oportunidade de novos laços traz a expressão da sexualidade, pois o gozo sexual é "solidário a um semblante"(LACAN, 1971a/2009, p. 33), mas pode haver desencontros na formação da imagem corporal e dificuldades para se fazer esse semblante. Isso aponta para algo ocorrido no estádio do espelho, algo que vacila "como uma identificação, no sentido pleno que a análise atribui a esse termo, ou seja, a transformação produzida no sujeito quando ele assume uma imagem" (LACAN, 1949/1998, p. 97).

Concluindo, podemos dizer que a psicanálise pode contribuir no estudo da transexualidade com a ética de bem dizer o sintoma e o analista com sua falta-a-ser. Vimos no caso de Julia que tornar-se menino é sintoma, defesa contra a castração e apelo ao Outro do amor, apontando para a estrutura histérica. Para João, entretanto, a transexualidade é um sinthoma; nova amarração ao erro do nó borromeano, solução que criou para estar melhor no mundo, de maneira menos sofrida. Então, tornar-se homem parece cumprir funções diferentes nos dois exemplos trabalhados. Apesar da singularidade de cada um deles, ambos mostraram que o sexo biológico não coincide com o gênero escolhido pelo sujeito, pois, embora tenham nascido biologicamente mulheres, desejavam ser homens, apesar de suas estruturas clínicas diferentes. Terminamos com o Poema oblíquo, de João Nery (2012): 


\author{
é madrugada \\ mas não há madrugada \\ a noite há muito não dorme \\ venderam-na como se vendem estrelas mortas \\ e sexos usados. e carnes. e deuses. e almas de homens.
}

\title{
Referências bibliográficas
}

BENJAMIN, H. (1953) The transsexual phenomenon. New York: Julian Press, 1966. Disponível em: http://www.symposion.com/ijt/benjamin/index.htm. Acesso em: 26 junho 2017.

FREUD, S. (1924) A dissolução do complexo de Édipo. In: Edição Standard Brasileira das Obras Psicológicas Completas de Sigmund Freud. Rio de Janeiro: Imago, 1996, v. 19.

. (1925) Algumas consequências psíquicas da distinção anatômica entre os sexos. In: Edição Standard Brasileira das Obras Psicológicas Completas de Sigmund Freud. Rio de Janeiro: Imago, 1996, v. 19.

LACAN, J. (1949) O estádio do espelho como formador da função do eu. In: Escrito. Rio de Janeiro: Jorge Zahar Ed., 1998.

- (1956-77). O seminário, livro 4: a relação de objeto. Rio de Janeiro: Jorge Zahar Ed., 1995.

- (1959-60). O seminário livro 7: a ética da psicanálise. Rio de Janeiro: Jorge Zahar Ed., 2008.

. (1960). Observações sobre o relatório de Daniel Lagache. In: Escritos.

Rio de Janeiro: Jorge Zahar Ed., 1998.

Ed., 2005.

. (1962-63) O seminário, livro 10: a angústia. Rio de Janeiro: Jorge Zahar

(1971a) O seminário, livro 18: de um discurso que não fosse semblante.

Rio de Janeiro: Jorge Zahar Ed., 2009.

. (1971b) O seminário, livro 19: ...ou pior. Rio de Janeiro: Jorge Zahar Ed., 2012.

. (1973) O seminário, livro 11: os quatro conceitos fundamentais da psi-

canálise. Rio de Janeiro: Jorge Zahar Ed., 1998.

. (1974-75) O seminário, livro 23: o sinthoma. Rio de Janeiro: Jorge

Zahar Ed., 2007.

MILLOT, C. Extrasexo: ensaios sobre o transexualismo. São Paulo: Escuta, 1992.

NERY, J. Erro de pessoa. Rio de Janeiro: Record, 1984.

. Viagem solitária - Memórias de um transexual 30 anos depois. São

Paulo: Leya, 2011. 
. Poema oblíquo. Disponível em: http://revista.benfazeja.com.

br/2012/10/poemas-de-joao-nery.html. Acesso em: 26 junho 2017.

\title{
Sexo, gênero. Sintoma e sinthoma \\ Sex, gender. Symptom, sinthome
}

\begin{abstract}
resumo
Atualmente, ciência e tecnologia unidas podem mudar o corpo do ser falante gênero -, produzindo criaturas capazes de realizar escolhas objetais com Freud, ou modalidades de gozo em Lacan, antes impedidas por sua biologia. A pulsão ao tentar contornar o objeto $a$ vai enredando a trama do sujeito, transformandoo mal-estar do sintoma em um sinthoma particular. A autora apresenta o caso de uma adolescente de doze anos, que diz "não se sentir uma menina e quer ser um menino". Apresenta, também, em contraponto, o caso do primeiro homem trans brasileiro, que com uma laçada reinventa um lugar para si no mundo, com a expressão de seu sinthoma.
\end{abstract}

\section{palavras-chave:}

Psicanálise; transexualidade; sintoma; sinthoma.

\section{abstract}

Currently, science and technology together can change the body of the speaker - gender -producing creatures capable of object choices in Freud or enjoyment modalities in Lacan, impeded by their biology before.The drive, trying to outline the object $a$, will tangle the plot of the subject, turning the malaise symptom into a particular sinthome. The author presents the case of a twelve-year-old girl who says she "does not feel like a girl and wants to be a boy". It also presents, in counterpoint, the case of the first Brazilian transman, who in a loop reinvents a place for himself in the world, with the expression of his sinthome.

\section{keywords:}

Psychoanalysis; transexuality; symptom; sinthome.

\section{Recebido:}

$24 / 05 / 2017$

\section{Aprovado:}

02/07/2017 